\title{
Violência contra o idoso: perfil do agredido e do acusado/indiciado com base em registros policiais
}

\author{
Violence against the elderly: profile of the accused and the accused / \\ indicted on the basis of police records
}

\author{
Bianca de Oliveira Lovato', Emanuele Saul Saraiva", \\ Luciane Flores Jacobil', Olinda Barcellos ${ }^{\mathrm{IV}}$
}

\begin{abstract}
RESUMO
O objetivo deste estudo foi identificar a violência contra a pessoa idosa na cidade de Santa Maria/RS, por meio da verificação do perfil da vítima e da relação com o agressor. Para tanto, um estudo transversal e descritivo de análise documental foi elaborado e conduzido na Delegacia de Proteção à Pessoa Idosa de Santa Maria em um período de 3 anos (2015-2017). Foi realizada uma análise descritiva de todas as variáveis e teste não-paramétrico do Qui-quadrado. Verificou-se que o perfil do idoso vítima é predominantemente do sexo feminino, na faixa etária de 60 a 70 anos, da cor branca, estado civil solteiro(a)/Viúvo(a)/Divorciado(a), do ensino fundamental e que possui algum parentesco com o acusado. $O$ acusado/indiciado é na sua maioria do sexo masculino, solteiro, na faixa etária de 40 a 60 anos, da cor branca, possuindo o ensino fundamental. Constatou-se que os acusados/indiciados são em primeiro lugar os filhos e a violência mais registrada foi a de maus tratos.
\end{abstract}

Palavras-chave: Abuso do idoso; Violência; Crime; Delegacia de Polícia de Proteção do Idoso.

\begin{abstract}
The objective of this study was to identify violence against the elderly in the city of Santa Maria / RS, by verifying the victim's profile and the relationship with the aggressor. To this end, a cross-sectional and descriptive study of document analysis was conducted and conducted at the Santa Maria Police Department for the Elderly over a period of 3 years (2015-2017). A descriptive analysis of all variables and non-parametric Chi-square test were performed. It was verified that the profile of the elderly victim is predominantly female, in the age group of 60 to 70 years, of white color, marital status single / Widowed /Divorced, elementary school and who has some kinship with the accused. The accused / indicted is mostly male, single, in the age group of 40 to 60 years, of white color, possessing elementary education. It was found that the accused / the accused are in the first place the children and the most recorded violence was the one of mistreatment.
\end{abstract}

Keywords: Elder abuse; Violence; Crime; Elderly Protection Police Station. 


\section{INTRODUÇÃO}

É notório o aceleramento do envelhecimento da população brasileira e da expectativa de vida no Brasil, a qual, conforme o Instituto Brasileiro de Geografia e Estatística - IBGE (2013), vem aumentando de maneira rápida de 60,8 anos no ano de 2000 passou para 73,9 anos em 2010, com projeção que em 2060 a esperança de vida será de 81,2 anos. O envelhecimento da população decorre da queda da fecundidade e da mortalidade, da evolução da medicina e da qualidade de vida melhorada da população. O envelhecimento populacional é tema relevante de discussão, pois o idoso vem sendo inserido cada vez mais na sociedade brasileira (CAMARANO, 2003).

Estudos do IBGE (2013), relatam que os idosos correspondem a $11 \%$ do total da população Brasileira, e que em 2025 o Brasil será o $6^{\circ}$ país com a maior população de idosos do planeta, ou seja, $14 \%$ da população mundial. Ainda, segundo dados do IBGE, o Rio Grande do Sul é o Estado com maior número de idosos (9,3\%), seguido pelo Rio Janeiro (7,43\%), e o $3^{\circ}$ em expectativa de vida, ficando atrás do Distrito Federal (DF) e de Santa Catarina (SC).

Segundo o IBGE (2013), a população em Santa Maria - RS, pelo censo de 2010, é de 261.031 habitantes e a estimativa para 2017 é de 278.445 habitantes, sendo que 14\% da população é representada por idosos (idade igual ou superior a 60 anos). E também, Santa Maria em relação ao estado do Rio Grande do Sul é o $4^{\circ}$ município com índice de envelhecimento mais alto.

A Wold Health Organization (2017), define violência contra o idosos como "um ato único ou repetido, ou a falta de ação adequada, que ocorre em qualquer relacionamento em que existe uma expectativa de confiança e que cause danos ou sofrimento a uma pessoa idosa". E contra o idoso pode ser do tipo: física, psicológica, sexual, financeira, negligência, abandono e autonegligência (MINAYO, 2005).

Estudos referentes a esse tema têm sido raros na literatura (Duque et al, 2012; Rodrigues et al, 2017; Lopes et al, 2018; Apratto Júnior et al, 2010) em função da dificuldade do idoso se expressar nas situações de conflitos (Rodrigues et al, 2017) sentimento de culpa e vergonha da vítima (Inigaray, 2016) e por ocorrer principalmente no contexto familiar (RODRIGUES, 2017) 
Considerando o envelhecimento populacional, é de grande relevância a avaliação de documentos oficiais para caracterizar a violência contra o idoso do município, propiciando, desta forma, estatísticas para que o poder público possa tomar as devidas decisões. Portanto, identificar a violência contra a pessoa idosa na cidade de Santa Maria/RS, através da verificação do perfil da vítima e da relação com o agressor, é o objetivo principal deste estudo. Pretende-se também, apresentar o perfil do acusado/indiciado, verificar a relação entre a vítima e o acusado/indiciado e averiguar a prevalência das agressões sofridas, bem como as ações desenvolvidas em âmbito de proteção e prevenção à violência contra a pessoa idosa.

\section{MATERIAIS E MÉTODOS}

Trata-se de um estudo transversal, descritivo de análise documental, conduzido na Delegacia de Polícia de Proteção do Idoso de Santa Maria, onde foram analisados os boletins de ocorrência instaurados nos anos de 2015, 2016 e 2017. Foram incluídas as ocorrências registradas pelos idosos (com idade igual ou superior a 60 anos) e as ocorrências que se teve como crime: lesão corporal, maus tratos e vias de fato, sendo excluídos todos os outros tipos de crime.

Esse trabalho foi registrado no Gabinete de Projeto (GAP) do Centro de Ciências Naturais e Exatas (CCNE), submetido ao Comitê de Ética em Pesquisa (CEP) da UFSM para análise sendo aprovado conforme parecer CAEE n 79493517.0.0000.5346. Os aspectos éticos foram respeitados conforme resolução $n^{\circ} 466 / 12$ do Conselho Nacional de Saúde, do Ministério da Saúde, sobre Pesquisas envolvendo seres Humanos.

Salienta-se que esta pesquisa não envolve intervenções em seres humanos, apenas dados referentes aos avaliados em inquéritos policiais. Os dados coletados foram armazenados em uma planilha eletrônica no software Excel 2010 pelo pesquisador. Analisaram-se 281 procedimentos policiais, dos quais se retiraram informações pertinentes sobre o perfil da vítima, do agressor e do crime ocorrido, formando um banco de dados. 
Separaram-se as variáveis estudadas em quatro categorias distribuídas em variáveis da vítima (sexo, idade, cor, estado civil, escolaridade, condição física e fato do registro); do acusado e do indiciado (sexo, idade, cor, estado civil, escolaridade, vínculo empregatício, apresenta algum tipo de problema (usuário de drogas, alcoólatra, etc.), antecedentes policiais); e do crime que levou a ocorrência policial (tipo da ocorrência policial, bairro, área, local, interesse em processar o indiciado, interesse em medidas protetivas, se foi retirada a queixa, se foi a vítima que desejou registrar ocorrência, parentesco, quantidade de pessoas indiciadas, número de dias do ocorrido até o registro, número de dias do registro até a autuação, número de dias até a conclusão da ocorrência, se foi indiciado ou não, meio empregado, causas presumíveis, turno do dia).

A partir das distribuições absolutas e relativas, foi realizado o teste não paramétrico Qui-Quadrado de Pearson para avaliar a associação entre as mesmas sendo considerado o nível de significância de 5\%. As análises foram realizadas através do software Statistica 9.0

\section{RESULTADOS}

Encontrou-se no período de 2015 a 2017 um total de 1.790 ocorrências registradas de todos os tipos de crimes. Entre os crimes de maus tratos (95), vias de fato (51) e lesão corporal (167) obteve-se 313 ocorrências instauradas, dos quais, em decorrência da falta de alguns procedimentos policiais e também a exclusão de denúncias de maus tratos em clínicas de idosos (quatro casos) se obteve um total de 281 ocorrências analisadas.

Das 281 ocorrências policias avaliadas, verificou-se um predomínio de idosos vítimas de violência do sexo feminino (59,43\%), na faixa etária de 60 a 70 anos (56,63\%), da cor branca (91,97\%), estado civil solteiro(a)/Divorciado(a)/Viúvo(a) (53,76\%), escolaridade ensino fundamental (63,53\%) e que possui algum parentesco com o acusado (71,89\%), conforme apresentado na Tabela 1. A idade média dos idosos vítimas de violência foi de 71 anos, com idade mínima de 60 anos e idade máxima de 97 anos. 
Tabela 1 - Associação entre o tipo de inquérito e caraterísticas da vítima de violência no munícipio de Santa Maria - RS segundo ocorrências policiais da Delegacia de Proteção de Idoso, nos anos de 2015 a 2017

\begin{tabular}{|c|c|c|c|c|c|c|}
\hline \multirow[b]{2}{*}{ Variável } & \multirow[b]{2}{*}{ Categoria } & \multirow[b]{2}{*}{$\mathrm{n}$} & \multirow[b]{2}{*}{$\%$} & \multicolumn{2}{|c|}{ Tipo de procedimento } & \multirow[b]{2}{*}{ p-valor } \\
\hline & & & & $\begin{array}{l}\text { Inquérito } \\
\text { policial (\%) }\end{array}$ & $\begin{array}{c}\text { Termo } \\
\text { circunstanciado (\%) }\end{array}$ & \\
\hline \multirow[t]{2}{*}{ Sexo } & Feminino & 167 & 59,43 & $115(68,45)$ & $52(46,01)$ & $0,00017 *$ \\
\hline & Masculino & 114 & 40,57 & $53(31,55)$ & $61(53,99)$ & \\
\hline \multirow[t]{3}{*}{ Idade } & 60 a 70 & 158 & 56,63 & $78(46,70)$ & $80(71,43)$ & 0,00021 * \\
\hline & 71 a 80 & 74 & 26,52 & $53(31,74)$ & $21(18,75)$ & \\
\hline & 81 ou mais & 47 & 16,85 & $36(21,56)$ & $11(9,82)$ & \\
\hline \multirow[t]{2}{*}{ Cor } & Branca & 252 & 91,97 & $144(88,88)$ & $108(96,43)$ & $0,02396 *$ \\
\hline & Preta/ Parda & 22 & 8,03 & $18(11,12)$ & $4(3,57)$ & \\
\hline \multirow[t]{2}{*}{ Estado civil } & Solt./Divorc./Viúvo(a) & 150 & 53,76 & $85(50,89)$ & $65(58,04)$ & 0,24115 \\
\hline & $\begin{array}{l}\text { /Casado(a)/ } \\
\text { União Estável }\end{array}$ & 129 & 46,24 & $82(49,11)$ & $47(41,96)$ & \\
\hline \multirow[t]{3}{*}{$\begin{array}{l}\text { Cor dos } \\
\text { olhos }\end{array}$} & Castanho & 222 & 82,22 & $130(82,28)$ & $92(82,14)$ & 0,80977 \\
\hline & Azul & 29 & 10,74 & $18(11,39)$ & $11(9,82)$ & \\
\hline & Verde & 19 & 7,04 & $10(6,33)$ & $9(8,03)$ & \\
\hline \multirow[t]{4}{*}{ Escolaridade } & Ensino Fundamental & 162 & 63,53 & $94(65,28)$ & $68(61,26)$ & 0,55315 \\
\hline & Ensino Médio & 43 & 16,86 & $21(14,58)$ & $22(19,82)$ & \\
\hline & Ensino Superior & 20 & 7,84 & $10(6,94)$ & $10(9,01)$ & \\
\hline & Não alfabetizado(a) & 30 & 11,76 & $19(13,19)$ & $11(9,91)$ & \\
\hline \multirow{2}{*}{$\begin{array}{l}\text { Parentesco } \\
\text { com acusado }\end{array}$} & Sim & 202 & 71,89 & $143(85,12)$ & $59(52,21)$ & $0,0000 *$ \\
\hline & Não & 79 & 28,11 & $25(14,88)$ & $54(47,79)$ & \\
\hline
\end{tabular}

Há um predomínio da realização de inquéritos policial em idosos do sexo feminino $(68,45 \%)$ e no sexo masculino, o termo circunstanciado $(53,99 \%)$. Verificou associação significativa entre o tipo de procedimento e as variáveis sexo $(p$-valor $<0,01)$, idade ( $p$-valor $<0,01)$, cor $(p$-valor $<0,05)$ e parentesco $(p$-valor $<0,01)$ não havendo associação significativa com as demais variáveis. 
Em relação aos procedimentos adotados após o registro de ocorrência, se obteve uma prevalência do tipo inquéritos policiais (casos mais sérios, cuja pena é superior a dois anos) representando $59,79 \%$ do total analisado. Entre os fatos dos registros (crimes) estudados houve prevalência em crimes do tipo lesão corporal $(53,02 \%)$, seguido de maus tratos $(30,96 \%)$ e vias de fato $(16,01 \%)$, conforme Tabela 2 . Dentre as ocorrências instauradas e que se teve o indiciamento, tem-se a prevalência do crime de maus tratos (43,68\%), vias de fato $(24,44 \%)$ e lesão corporal $(22,82 \%)$, evidenciando que os crimes de maus tratos são os que apresentam maior quantidade de pessoas indiciadas. A maioria dos crimes ocorreram na área urbana do município $(97,16 \%)$ e na residência da vítima (79,71\%). Verificou-se que foi a vítima que teve a iniciativa de registrar a ocorrência policial (55,52\%), no dia em que a mesma ocorreu, sendo que $68,68 \%$ das vítimas desejou processar o acusado, sem o interesse de medidas protetivas $(71,89 \%)$, dados esses que podem ser observados na Tabela 2.

Dentre as ocorrências instauradas somente 26,33\% dos acusados foram indiciados, havendo então prevalência no não indiciamento dos acusados. 
Tabela 2 - Caracterização das ocorrências policiais avaliadas da Delegacia de Proteção ao Idoso do munícipio de Santa Maria - RS nos anos de 2015 a 2017

\begin{tabular}{|c|c|c|c|}
\hline Variável & Categoria & $\mathrm{n}^{*}$ & $\%$ \\
\hline \multirow[t]{2}{*}{ Tipo de ocorrência } & Inquérito policial & 168 & 59,79 \\
\hline & Termo Circunstanciado & 113 & 40,21 \\
\hline \multirow[t]{3}{*}{ Fato do registro } & Lesão Corporal & 149 & 53,03 \\
\hline & Maus Tratos & 87 & 30,96 \\
\hline & Vias de fato & 45 & 16,01 \\
\hline \multirow[t]{3}{*}{ Ano da ocorrência } & 2015 & 105 & 37,37 \\
\hline & 2016 & 105 & 37,37 \\
\hline & 2017 & 71 & 25,26 \\
\hline \multirow[t]{12}{*}{ Mês do ocorrido } & Janeiro & 14 & 4,98 \\
\hline & Fevereiro & 23 & 8,18 \\
\hline & Março & 28 & 9,96 \\
\hline & Abril & 21 & 7,47 \\
\hline & Maio & 15 & 5,34 \\
\hline & Junho & 31 & 11,04 \\
\hline & Julho & 23 & 8,18 \\
\hline & Agosto & 17 & 6,05 \\
\hline & Setembro & 24 & 8,54 \\
\hline & Outubro & 27 & 9,61 \\
\hline & Novembro & 36 & 12,82 \\
\hline & Dezembro & 22 & 7,83 \\
\hline \multirow[t]{3}{*}{ Área do ocorrido } & Rural & 4 & 1,42 \\
\hline & Suburbana & 4 & 1,42 \\
\hline & Urbana & 273 & 97,16 \\
\hline \multirow[t]{9}{*}{ Local do ocorrido } & Residência da vítima & 224 & 79,71 \\
\hline & Instituição de saúde & 5 & 1,78 \\
\hline & Via pública & 33 & 11,74 \\
\hline & Área externa de moradia & 4 & 1,42 \\
\hline & Residência do acusado & 3 & 1,07 \\
\hline & Interior de coletivos & 1 & 0,36 \\
\hline & Estabelecimento comercial & 7 & 2,49 \\
\hline & Clínica de idosos & 2 & 0,71 \\
\hline & Estabelecimento público & 2 & 0,72 \\
\hline \multirow[t]{3}{*}{ Desejou processar? } & Sim & 193 & 68,68 \\
\hline & Não & 47 & 16,73 \\
\hline & Sem reposta & 41 & 14,59 \\
\hline \multirow[t]{3}{*}{ Desejou medidas protetivas? } & Sim & 38 & 13,52 \\
\hline & Não & 202 & 71,89 \\
\hline & Sem resposta & 41 & 14,59 \\
\hline \multirow[t]{3}{*}{ Retirada da ocorrência? } & Sim & 87 & 30,96 \\
\hline & Não & 179 & 63,70 \\
\hline & Sem resposta & 15 & 5,34 \\
\hline \multirow{4}{*}{$\begin{array}{l}\text { Vítima que teve vontade } \\
\text { de registrar? } \\
\text { Quantos acusados? }\end{array}$} & Sim & 156 & 55,52 \\
\hline & Não & 125 & 44,48 \\
\hline & 1 a 2 & 273 & 97,85 \\
\hline & 3 a 4 & 6 & 2,15 \\
\hline \multirow{3}{*}{$\begin{array}{l}\text { Acusado indiciado? } \\
\text { (Inquérito policial) } \\
\text { Termo circunstanciado }\end{array}$} & $\operatorname{Sim}$ & 74 & 26,33 \\
\hline & Não & 94 & 33,45 \\
\hline & & 113 & 40,22 \\
\hline
\end{tabular}

* $\mathrm{n}$ - Não é o mesmo em cada categoria devido a dados faltantes. 
Segundo a Tabela 2, nos anos de 2015 e 2016 se teve um total de 105 (37,37\%) procedimentos instaurados e concluídos, já no ano de 2017 se teve um total de 71 $(25,27 \%)$ procedimentos. Devido que os dados foram coletados em 2018, se tem a explicação dos poucos procedimentos policiais analisados, pois possuíam muitos inquéritos ainda em andamento. Foram 74 inquéritos onde um total de 83 acusados foram indiciados, isto devido ao fato em que haviam inquéritos com mais de um acusado.

Pode-se observar na Tabela 3, que as características prevalentes do acusado e indiciado são as mesmas em todas as variáveis, portanto o perfil do acusado/indiciado é do sexo masculino (57,19\%), de estado civil solteiro (68,97\%), na faixa etária de 40 a 60 anos $(42,80 \%)$, de cor branca $(88,89 \%)$, com escolaridade do ensino fundamental (52,13\%). A maioria dos acusados e indiciados possui algum vínculo empregatício e não possuem antecedentes policiais. Entre os que apresentam algum problema, há um predomino de pessoas que são usuários de drogas/álcool. 
Tabela 3 - Características do acusado e do indiciado de violência no munícipio de Santa Maria - RS segundo ocorrências policiais da Delegacia de Proteção de Idoso, nos anos de 2015 a 2017

\begin{tabular}{|c|c|c|c|c|c|}
\hline \multirow{2}{*}{ Variável } & \multirow{2}{*}{ Categoria } & \multicolumn{2}{|c|}{ Acusado } & \multicolumn{2}{|c|}{ Indiciado } \\
\hline & & $\mathrm{N}$ & $\%$ & $\mathrm{n}$ & $\%$ \\
\hline \multirow[t]{2}{*}{ Sexo } & Masculino & 167 & 57,19 & 45 & 54,22 \\
\hline & Feminino & 125 & 42,81 & 38 & 45,78 \\
\hline \multirow[t]{4}{*}{ Idade } & $<40$ & 104 & 38,38 & 28 & 33,73 \\
\hline & 40 a 60 & 116 & 42,80 & 37 & 44,58 \\
\hline & 61 a 80 & 50 & 18,45 & 18 & 21,69 \\
\hline & $>81$ & 1 & 0,37 & 0 & 0 \\
\hline \multirow[t]{3}{*}{ Cor } & Branca & 224 & 88,89 & 71 & 85,54 \\
\hline & Preta & 23 & 9,13 & 10 & 12,05 \\
\hline & Amarela/Parda & 5 & 1,98 & 2 & 2,41 \\
\hline \multirow[t]{2}{*}{ Estado Civil } & Solt./Divorc./Viúvo & 180 & 68,97 & 54 & 65,85 \\
\hline & Casado(a)/União Estável & 81 & 31,03 & 28 & 34,15 \\
\hline \multirow[t]{4}{*}{ Escolaridade } & Ensino Fundamental & 122 & 52,13 & 44 & 56,41 \\
\hline & Ensino Médio & 75 & 32,05 & 24 & 30,77 \\
\hline & Ensino Superior & 31 & 13,25 & 8 & 10,26 \\
\hline & Semialfabetizado & 6 & 2,56 & 2 & 2,56 \\
\hline \multirow{2}{*}{$\begin{array}{l}\text { Vínculo } \\
\text { empregatício? }\end{array}$} & Sim & 106 & 72,60 & 39 & 66,10 \\
\hline & Não & 40 & 27,40 & 20 & 33,90 \\
\hline \multirow{3}{*}{$\begin{array}{l}\text { Apresenta } \\
\text { problemas? }\end{array}$} & Não apresentou & 237 & 78,48 & 56 & 65,88 \\
\hline & Usuários de drogas/substâncias & 46 & 15,23 & 21 & 24,71 \\
\hline & Psicológicos & 19 & 6,29 & 8 & 9,41 \\
\hline \multirow{2}{*}{$\begin{array}{l}\text { Antecedentes } \\
\text { policiais? }\end{array}$} & Sim & 82 & 38,14 & 45 & 60,81 \\
\hline & Não & 133 & 61,86 & 29 & 39,19 \\
\hline \multirow[t]{2}{*}{ Filhos } & $\operatorname{Sim}$ & - & - & 48 & 63,16 \\
\hline & Não & - & - & 28 & 36,84 \\
\hline
\end{tabular}

* não é o mesmo em cada categoria devido a dados faltantes.

O crime de maus tratos $(45,78 \%)$ é o que apresenta maior prevalência nas ocorrências onde o acusado é indiciado. Os meios empregados do crime mais prevalentes são os de força física (40,22\%), negligência (22,83\%) e ofensas $(21,74 \%)$. Em relação às causas presumíveis a prevalência é de questões familiares $(25,61 \%)$, desavenças $(15,85 \%)$ e despreocupação com a vítima idosa $(15,85 \%)$ e tem-se um predomínio de que os crimes ocorrem pelo dia (78,21\%), dados esses apresentados na tabela 4. 
Tabela 4 - Caracterização dos inquéritos policiais instaurados e indiciados avaliadas da Delegacia de Proteção ao Idoso do munícipio de Santa Maria - RS de 2015 a 2017

\begin{tabular}{llrr}
\hline Variável & Categoria & $\mathrm{n}$ & $\%$ \\
\hline Fato do registro & Maus tratos & 38 & 45,78 \\
& Lesão corporal & 34 & 40,96 \\
& Vias de fato & 11 & 13,25 \\
\hline Meio empregado & Força física & 37 & 40,22 \\
& Negligência & 21 & 22,83 \\
& Ofensas & 20 & 21,74 \\
& Inst. Contundente/Cortante & 12 & 13,04 \\
& Financeiro/Fraude & 2 & 2,17 \\
\hline Causas presumíveis & Questões familiares & 21 & 25,61 \\
& Desavenças & 13 & 15,85 \\
& Despreocupação com a vítima & 13 & 15,85 \\
& Indiciado é usuário de drogas/álcool & 11 & 13,41 \\
& Apropriação de bens da vítima & 9 & 10,98 \\
& Agressividade do indiciado & 8 & 9,76 \\
& Outros & 7 & 8,54 \\
\hline Ocorreu em que turno? & Dia & 61 & 78,21 \\
& Noite & 17 & 21,79 \\
\hline Prisão & Sim & 4 & 5,06 \\
& Não & 75 & 94,94 \\
\hline * $n$ - Não é o mesmo em cada categoria devido a dados faltantes. & &
\end{tabular}

Há um predomínio $(97,85 \%)$ de ocorrências onde uma ou duas pessoas são acusadas, e somente $2,15 \%$ possui 3 ou mais denunciados. Na maioria dos casos o indiciado não é preso $(94,94 \%)$ sendo que, dos quatro casos em que ocorreu a prisão do indiciado, um foi pelo crime de maus tratos, um por vias de fato e dois por lesão corporal.

\section{DISCUSSÃO}

Uma tentativa de inibir a violência contra o idoso foi por meio de criações de leis, decretos, estatutos que servem, também, como medidas para a inserção do idoso na sociedade. Uma das primeiras medidas elaboradas foi a Constituição Federal de 1988, que no art. 230, enuncia "A família, a sociedade e o Estado têm o dever de amparar as pessoas idosas, assegurando sua participação na comunidade, defendendo sua dignidade e bem-estar e garantindo-Ihes o direito à vida".

No decorrer dos anos, surge a lei $n^{\circ} 8.842$, de 4 de janeiro de 1994, que dispõe sobre a Política Nacional do Idoso e cria o Conselho Nacional do Idoso, pelo qual se assume como "idosa" uma pessoa com idade igual ou superior a 60 anos. Ademais, a 
norma objetiva assegurar os direitos sociais, criando condições para promover autonomia, integração e participação dos idosos na sociedade.

A partir de 1994, através de decretos e leis, foram fundados órgãos policiais especializados no atendimento ao idoso, sendo um deles, a Delegacia de Polícia de Proteção ao Idoso (DPPI). Em 2003, foi promulgada a Lei 10.741 de $1^{\circ}$ de outubro, que estabeleceu o Estatuto do Idoso, sendo uma conquista que regulou os diretos das pessoas idosas. Com a criação deste Estatuto estudos sobre a violência contra o idoso tiveram crescimento.

Atualmente, no estado do Rio Grande do Sul existem duas Delegacias de Polícia de Proteção ao Idoso, à primeira foi criada na cidade de Porto Alegre (RS) pelo decreto $n^{\circ} 35.548$ de 21 de Setembro de 1994 e a segunda em Santa Maria (RS) pelo decreto $n^{\circ}$ 42.913, de 17 de Fevereiro de 2004 que compete prevenir e reprimir, concorrentemente com as demais Delegacias de Polícia do Município de Santa Maria, crimes em que o sujeito passivo do delito seja pessoa idosa, promovendo-Ihe, ainda, auxílio, orientação e encaminhamento, quando necessário, aos demais órgãos competentes.

No presente estudo encontraram-se algumas limitações, como por exemplo: dados incompletos nas ocorrências policiais, dificuldade de encontrar todos os inquéritos e a falta de mais variáveis, que possam ser analisadas para um maior entendimento sobre o assunto.

O estudo realizado representa uma análise fundamental para a compreensão do envelhecimento da população. Constatou-se que $5 \%$ da população idosa no munícipio de Santa Maria - RS registraram ocorrência policial durante os anos de 2015 a 2017, analisando no decorrer desses anos o percentual vem decaindo, onde implica que há uma diminuição de ocorrências registradas. Esse percentual é superior ao valor obtido em um estudo realizado no Distrito Federal, o qual detectou que 3,84\% dos idosos registram alguma ocorrência policial (IBGE, 2010).

Tratando-se do tipo de ocorrência, (Segundo aos tipos de ocorrências) observouse o predomínio de inquéritos policiais, quantificados em 168 casos (59,79\%), enquanto que em 113 (40,21\%), foi apenas lavrado o termo circunstanciado. Estudo realizado por 
Garcia et al (2009) sobre a violência intrafamiliar traz o resultado de que $87,5 \%$ dos acusados respondem o termo circunstanciado, contrapondo o resultado apresentado.

Entre os tipos de crimes analisados, verificou-se uma prevalência do crime de lesão corporal (53\%), seguido de maus tratos (31\%) e vias de fato (16\%). O estudo realizado no Distrito Federal apresentou crime lesão corporal como de maior prevalência (IBGE, 2010). Embora o crime de lesão corporal tenha demonstrado a maior ocorrência nesta investigação, aquele com maior prevalência de pessoas indiciadas foi o de maus-tratos contra o idoso.

No presente estudo, houve predominância de idosos vítima do sexo feminino, na faixa etária de 60 a 70 anos, com média de idade de 71 anos, solteiras, de cor branca e de escolaridade baixa (ensino fundamental). Alguns trabalhos reforçam as características predominantes do idoso vítima de violência, como um estudo realizado no município de Criciúma (SC) que mostrou a prevalência de idosos do sexo feminino, de escolaridade baixa, com média de idade de 73 anos (Apratto, 2010), outro estudo realizado em São Paulo mostrou a prevalência do sexo feminino, de faixa etária entre 60 a 74 anos, de escolaridade baixa (Sanches, 2006), assim como a pesquisa realizada nos municípios de Ribeirão Preto (SP), João Pessoa (PB) e Teresina (PI) que mostrou a predominância em idosos do sexo feminino, na faixa etária de 60 a 69 anos, casadas, e de escolaridade baixa ( $1^{\circ}$ grau completo) (RODRIGUES et al, 2017). Contrapondo-se aos resultados neste estudo achados, tem-se uma pesquisa realizada em Niterói (RJ) no ano de 2006, que mostrou a prevalência em idosos de cor de pele negros/mulatos (APRATTO, 2010). A literatura também apresenta contextos em que houve prevalência de idosos vítimas casados(as) (IBGE, 2010; GARCIA et al, 2009). Gacioli e Rodrigues (2008) e Rodrigues et al (2017), informaram que, na análise dos laudos de sua pesquisa, ocorreu maior proporção de homens vítimas de violência. É possível notar que, na maioria dos estudos, o sexo feminino, a idade (60 a 70 anos) e a escolaridade (ensino fundamental) se mantiveram predominantes entre as vítimas.

No perfil do acusado/indiciado deste estudo, verificaram-se como características de maior recorrência: o sexo masculino, a faixa etária entre 40 e 60 anos, a escolaridade de ensino fundamental e o pertencimento à própria família da vítima (frequentemente 
filhos) - aspectos também reforçados por estudos no Distrito Federal (IBGE, 2010), Criciúma (SC) (Garcia et al, 2009), Ribeirão Preto (SP), João Pessoa (PB) e Teresina (PI) (RODRIGUES et al, 2017). Já em outro, realizado no Rio de Janeiro (Souza et al, 2008), teve-se a prevalência do acusado sendo do sexo feminino.

Neste estudo também se relatou que os acusados/indiciados não apresentavam algum tipo de problema, em linhas gerais. Contudo, entre aqueles que os possuíam, houve a prevalência de consumo de alguma substância, seja álcool ou drogas. Nos casos em que o acusado apresentava algum problema, seja relacionado ao âmbito psicológico ou ao uso de substâncias, constatou-se recorrência de indivíduos da própria família da vítima, fazendo com que a mesma retirasse a ocorrência e não desse continuidade ao inquérito. Apesar da rede de apoio conferida pela família, percebeuse que seus membros, por vezes, são os autores do ato de violência (CARNEY, KAHAN e PARIS, 2003). Em concordância com a literatura, alguns dos fatores desencadeadores da agressão contra o idoso foram: uso de substâncias psicoativas, consumo abusivo de álcool e depressão (RIBOT et al, 2015).

Encontrou-se que, em 79,72\% (224) das ocorrências instauradas, a violência sucedeu na residência da vítima. Corroborando tal resultado, tem-se o estudo realizado em Ribeirão Preto (SP), João Pessoa (PB) e Teresina (PI) (Rodrigues et al, 2017), o qual mostra o predomínio residencial, com aproximadamente $75 \%$, entre os locais onde se praticam as agressões.

Os achados revelam que a violência contra o idoso ocorre na própria residência e os acusados/indiciados têm baixa escolaridade. Alguns indicativos da violência podem ser a falta de preparo das famílias, o estresse do dia-a-dia e o associado à condição financeira, além da dependência do idoso para poder exercer suas atividades. 


\section{CONCLUSÃO}

A pesquisa realizada conseguiu atingir seus principais objetivos que eram de traçar um perfil da vítima idosa e sua relação com o acusado/indiciado. O resultado encontrado foi o mesmo entre vários outros estudos, indicando que há uma tendência da violência em um perfil de idoso do acusado/indiciado.

É percebido que ainda existe muito a ser melhorado em relação à documentação da violência contra o idoso, pois existe um grande atraso neste assunto, por mais que existam hoje políticas que os protejam, elas devem ser mais revisadas e melhoradas como, por exemplo, o acesso mais facilitado do idoso à delegacia, a criação de uma padronização das ocorrências policias, com mais informações sobre o idoso e o acusado, podendo avaliar o real motivo da violência.

Os resultados encontrados neste estudo mostram a importância da avaliação estatística de dados gerados por órgãos oficiais para o conhecimento do problema em si e como preveni-lo (criando políticas públicas). Como a maioria das ocorrências policias analisadas são envolvendo familiares, sugere-se a criação de programas de apoio a familiares cuidadores de idosos. Também se sugere a continuidade de pesquisas sobre a violência contra o idoso junto à delegacia de policia, sendo criado um banco de dados para extração de mais variáveis que possam ser implementadas análises, verificando tendências do perfil, tipo de violência, local onde ocorrem e o real problema da violência para que possa ser combatida antes de ser realizada, conscientizando as pessoas sobre o papel do idoso na sociedade e mudando a atual realidade. 


\section{REFERÊNCIAS}

APRATTO JÚNIOR PC. A violência contra idosos nas áreas de abrangência do Programa Saúde da Família de Niterói (RJ, Brasil). Rev Ciênc saúde coletiva [Internet]. 2010 sept [cited 2018 jun 1];15(6):2883-2995. Available from: http://www.scielo.br/scielo.php?script=sci_arttext\&pid=S1413-81232010000600037

CAMARANO AA. Mulher idosa: suporte familiar ou agente de mudança? Estud. av. [Internet]. 2003 sept-dec [cited 2017 sept 15];17(49):35-63. Available from: http://www.scielo.br/scielo.php?script=sci_arttext\&pid=S0103-40142003000300004

CARNEY MT, KAHAN FS, PARIS BE BE. Elder Abuse: Is Every Bruise a Sign of Abuse? Mt Sinai J Med. 2003 Mar;70(2):69-74

CONSTITUIÇÃO DA REPÚBLICA FEDERATIVA DO BRASIL DE 1988 [Internet]. Brasília: Supremo Tribunal Federal. Secretaria de Documentação. 2019 [cited 2018 jun 23]. Available from:

https://www.stf.jus.br/arquivo/cms/legislacaoConstituicao/anexo/CF.pdf

DECRETO N. 35.548, de 21 DE SETEMBRO DE 1994. Cria a Delegacia de Polícia de Proteção ao Idoso e amplia a competência da Delegacia da Mulher, no Município de Porto Alegre. Assembleia Legislativa do Estado do Rio Grande do Sul, Porto Alegre (RS). 1994 sept 21.

DECRETO N. 42.913 DE 17 DE FEVEREIRO DE 2004. Institui a Delegacia de Polícia de Proteção ao Idoso no Município de Santa Maria, e confere outras providências. Assembleia Legislativa do Estado do Rio Grande do Sul, Porto Alegre (RS). 2004 feb 17.

DUQUE AM, LEAL MCC, MARQUES APO, ESKINAZI FMV, DUQUE AM. Violência contra idosos no ambiente doméstico. Rev Ciência e Saúde. 2012 [cited 2019 oct 03];17(8):2199-2208.

GACIOLI CCLO, RODRIGUES RAP. Ocorrência de maus-tratos em idosos no domicilio. Rev Latino-Am Enfermagem [Internet]. 2008 [cited 2018 jun 1];16(3):6. Available from: http://www.scielo.br/pdf/rlae/v16n3/pt_21.pdf

GARCIA SS, COMIM CM, ROSA MI, XAVIER FMF, QUEVEDO J. Violência intrafamiliar contra idosos: perfil do indiciado e agredido. ACM arq catarin med [Internet]. 2009 ouct-dec [cited 2018 jun 1];38(4):25-30. Available from: http://www.acm.org.br/revista/pdf/artigos/766.pdf.

IRIGARAY TQ, ESTEVES CS, PACHECO JTB, GRASSI-OLIVEIRA R, ARGIMON IIL. Maus-tratos contra idosos em Porto Alegre, Rio Grande do Sul: um estudo documental. Rev Estudos de Psicologia. 2016 [cited 2019 oct 3];33(3):543-551. 
INSTITUTO BRASILEIRO DE GEOGRAFIA E ESTATÍSTICA. Diretoria de Pesquisas [Internet]. Projeção da população do Brasil por sexo e idade para o período de 2000/2060 e projeção da população das unidades da federação por sexo e idade para o período de 2000/2030. 2013 [cited 2017 sept 18]. Available from: ftp://ftp.ibge.gov.br/Projecao_da_Populacao/Projecao_da_Populacao_2013/nota_meto dologica_2013.pdf .

INSTITUTO BRASILEIRO DE GEOGRAFIA E ESTATÍSTICA. Diretoria de Pesquisas [Internet]. Censo $\mathbf{2 0 1 0}$ [cited 2018 jun 1]. Available from: https://cidades.ibge.gov.br/brasil/rs/santa-maria/panorama

LEI N· 8.842 DE 4 DE JANEIRO DE 1994. Dispõe sobre a política nacional do idoso, cria o Conselho Nacional do Idoso e dá outras providências. Diário Oficial da União (Brasília). 1994 jan 4.

LEI N. 10.741 DE $1^{\circ}$ DE OUTUBRO DE 2003. Dispõe sobre o Estatuto do Idoso e dá outras providências. Diário Oficial da União (Brasília). 2003 out 1.

LOPES EDS, FERREIRA AG, PIRES CG, MORAES MCS, ELBOUX MJ. Maus-tratos a idosos no Brasil: uma revisão integrativa. Rev Bras Geriatr Gerontol. 2018 [cited 2019 oct 3];21(5):652-662.

MINAYO MCS. Violência contra idosos: o avesso do respeito à experiência e à sabedoria [Internet]. 2.ed. Brasília: Secretaria Especial dos Direitos Humanos; 2005 [cited 2017 sept 1]. Available from:

http://www.observatorionacionaldoidoso.fiocruz.br/biblioteca/_livros/18.pdf

RESOLUÇÃO N. 466 DE 12 DE DEZEMBRO DE 2012. Diretrizes e normas regulamentadoras de pesquisas envolvendo seres humanos. Diário Oficial da União (Brasília). 2012 dez $12 . \quad$ Available from: https://bvsms.saude.gov.br/bvs/saudelegis/cns/2013/res0466_12_12_2012.html

RIBOT VC, ROUSSEAUX E, GARCÍA TC, ARTEAGA E, RAMOS ME, ALFONSO M. Psychological the most common elder abuse in a Havana neighborhood. MEDICC Rev [Internet]. 2015 [cited 2018 jun 1];17(2):39-43. Available from: http://www.medicc.org/mediccreview/index.php?issue=34\&id=458\&a=va

RODRIGUES RAP, MONTEIRO EA, SANTOS AMR, PONTES MLF, FHON JRS, BOLINA AF et al. Violência contra idosos em três municípios brasileiros. Rev Bras Enferm [Internet]. 2017 apr [cited 2018 jun 1];70(4):783-91.Available from: www.scielo.br/pdf/reben/v70n4/pt_0034-7167-reben-70-04-0783.pdf 
SANCHES PARA. A violência doméstica contra idosos no município de São Paulo Estudo SABE, 2000 [dissertation] [Internet]. São Paulo: Universidade de São Paulo; 2006. [cited 2017 sept 10]. 83p. Available from: http://www.teses.usp.br/teses/disponiveis/6/6132/tde-02112006-073951/en.php.

SOUZA ER, RIBEIRO AP, ATIE S, DE SOUZA AC, MARQUES CC. Rede de proteção aos idosos do Rio de Janeiro: um direito a ser conquistado. Ciênc. saúde coletiva [Internet]. 2008 [cited 2018 jun 1];13(4):1153-1163. Available from: http://www.scielo.br/pdf/csc/v13n4/11.pdf

WORLD HEALTH ORGANIZATION. Ageing and life-course (Health Topics): Elder abuse. 2017 [cited 2019 may 14]. Available from: https://www.who.int/ageing/projects/elder_abuse/en/. 